\title{
Growth and branching habit of rooted cuttings collected from epicormic shoots of Betula pendula Roth
}

\author{
A. D. CAMERON ${ }^{1}$ and H. SANI ${ }^{2}$ \\ 1 Department of Forestry, University of Aberdeen, Aberdeen AB9 2UD, Scotland, U.K. \\ ${ }^{2}$ Centre for Applied Sciences, Universiti Pertanian Malaysia, Bintulu 97008, Sarawak, Malaysia
}

Received August 18, 1993

\begin{abstract}
Summary
Patterns of shoot growth and branching were studied over two growing seasons in rooted cuttings collected from both epicormic shoots and seedlings of Betula pendula Roth. Epicormic shoots were induced to sprout on stumps and small logs of 5-, 10- and 30-year-old trees. The use of epicormic shoots enhanced the rooting capacity of stem cuttings collected from these shoots but did not appear to reverse the process of maturation. In this study, maturation was based on characteristics typical of mature trees but not necessarily those of the mother plant, because it was not possible to root cuttings, for comparison, from 5-, 10- and 30-year-old ortets, other than from epicormic shoots. There was evidence of the persistence of mature characteristics through an increase in shoot plagiotropism with incrcasing ortet age. Rooted cuttings from both seedlings and epicormic shoots, however, assumed an increasingly orthotropic habit with a smaller shoot angle at the end of the first growing season than at the beginning and this continued into the second growing season. Other indications of maturation, such as delayed bud flushing and the incidence of flowering with increasing ortet age, were also evident in rooted cuttings from epicormic shoots. There was a clear difference in branching habit depending on cutting source. Rooted cuttings derived from epicormic shoots produced nearly twice as many lateral branches compared with rooted cuttings collected from seedlings, but this was not an effect of maturation. There was some evidence that rooted cuttings derived from seedlings grew taller than rooted cuttings from epicormic shoots.
\end{abstract}

Keywords: juvenility, maturation, orthotropism, plagiotropism, rooting capacity.

\section{Introduction}

Epicormic shoots that originate at the base of a tree often have juvenile morphological and physiological characteristics compared with branches from other parts of the tree (e.g., Paton et al. 1970, Bonga 1982, Hackett 1985, Bonga 1987). Epicormic shoots, which are common in some hardwood genera (e.g., Quercus, Tilia and Eucalyptus), usually carry foliage of juvenile appearance and their cuttings are often easy to root (Davidson 1974, Hartney 1980, Harmer 1988). The juvenility of epicormic shoots has been exploited in combined tree improvement and breedingcloning programs because proven genotypes typically have lost the potential for high adventitious root formation with age (Zobel and Talbert 1984). Malure trees of Betula pendula Roth and Betula pubescens Ehrh. readily form epicormic shoots on cut stumps (e.g., Rinne et al. 1987), and stem cuttings collected from epicormic shoots root well (Cameron 1983). By comparison, cuttings collected from branches of seedlings older than three years root poorly if at all (Vaclav 1974, Cameron 1983). 